\title{
Corporate Governance, Kualitas Audit, Dan Kecenderungan Praktik Tax Avoidance
}

\author{
Fitria Nur Afni ${ }^{1)}$, Nanik Niandari ${ }^{2)}$, Handayani $^{3)}$ \\ ${ }^{1,2,3)}$ Akademi Akuntansi YKPN Yogyakarta \\ 1)email: fitriaafni0108@gmail.com \\ ${ }^{2)}$ email: niandarinanik@gmail.com \\ ${ }^{3)}$ email: handayani.ykpn@gmail.com
}

\begin{abstract}
This study aims to examine the effect of Corporate Governance $(C G)$ and audit quality on tax avoidance. This research was conducted using manufacturing companies listed on the IDX in the 2015-2019 period. Total sample used was 179 companies with total of 498 observations. The sampling method used was purposive sampling and data was analysed with multiple linear regression. Tax avoidance as dependent variable is measured by Effectice Tax Rate. Independent variables used in this research are corporate governance and audit quality. Corporate Governance as independent variable is measured by the proportion of independent commissioners, institutional ownership and audit committee. The result shows that the variable proportion of independent commissioners has a significant positive effect, institutional ownership has a significant negative effect, and the audit quality and audit committee variables have no significant effect on tax avoidance.
\end{abstract}

Keywords: Tax avoidance, Proportion of Independent Commisioners, Institutional Ownership, Audit Quality, Audit Committee, corporate governance

\section{A. PENDAHULUAN}

Pajak sebagai sumber pendapatan utama pemerintah digunakan untuk membiayai kebutuhan negara guna menyediakan sarana dan prasarana masyarakat. Bagi wajib pajak, pajak merupakan beban yang akan mengurangi laba yang tersedia untuk pemegang saham. Hal ini bisa mempengaruhi perilaku perusahaan terkait dengan pajak. Perilaku tersebut yakni melakukan tindakan yang cenderung mengurangi beban pajak tersebut baik dengan cara legal maupun ilegal (Jefri \& Khoiriyah, 2019).

Pengurangan beban pajak tersebut misalnya dilakukan dengan cara penghindaran pajak (tax avoidance) ataupun penggelapan pajak (tax evasion). Tax evasion merupakan tindakan untuk menghindari pajak yang melanggar hukum yakni dengan sengaja tidak melaporkan kewajiban atau menghilangkan bagian transaksi agar membuat tarif pajak menjadi rendah (Avriliusqa, 2020). Berbeda dengan tax evasion, tax avoidance merupakan penghindaran pajak yang dilakukan dengan cara mencari celah (loopholes) 
dari peraturan perpajakan yang berlaku.

Untuk mengurangi kecenderungan perilaku tax avoidance, pemerintah menegaskan perlunya pelaksanaan konsep Good Corporate Governance (GCG) di industri. Penerapan GCG di industri diharapkan dapat mempengaruhi kepatuhan dalam melaksanakan kewajiban perpajakan (Avianita \& Fitria, 2020). Friese, Link, dan Mayer (2006) dalam (Avriliusqa, 2020) menyatakan bahwa GCG memiliki pengaruh dalam pengambilan keputusan, termasuk keputusan dalam hal pemenuhan kewajiban perpajakan.

Penelitian tentang GCG dan penghindaran pajak telah banyak dilakukan dengan hasil yang masih belum konsisten. Artikel penelitian Avriliusqa (2020), Sandy \& Lukviarman (2015), Sumantri, Anggraeni, \& Kusnawan, (2018), serta Sunarsih \& Oktaviani (2016) memberikan hasil bahwa proporsi komisaris independen memilki pengaruh negatif terhadap penghindaran pajak. Di sisi lain, Akbar (2019); Setyawan (2018), Maretta, Widyastuti, \& Darmansyah (2019), serta Subagiastra, Arizona, \& Mahaputra (2016) hasil penelitiannya menunjukkan bahwa proporsi komisaris independen memiliki pengaruh positif terhadap penghindaran pajak. Namun, penelitian oleh Jefri \& Khoiriyah (2019), Avianita \& Fitria (2020), Dewi \& Sari (2015) menyimpulkan bahwa proporsi komisaris independen tidak mempunyai pengaruh terhadap penghindaran pajak.

Hal seperti di atas juga terjadi pada variabel kepemilikan institusional. Dari hasil penelitian yang dilakukan oleh Avriliusqa (2020) dan Maretta, Widyastuti, \& Darmansyah (2019) menghasilkan kesimpulan bahwa kepemilikan institusional memiliki pengaruh negatif terhadap tax avoidance. Hasil tersebut tidak sejalan dengan penelitian yang dilakukan oleh Subagiastra, Arizona, \& Mahaputra (2016), Avianita \& Fitria (2020), serta Marfirah \& BZ (2016) yang menyimpulkan bahwa kepemilikan institusional memiliki pengaruh negatif terhadap tindak penghindaran pajak. Demikian pula dengan hasil temuan Sandy \& Lukviarman (2015), Darma, Tjahjadi, \& Mulyani (2018), serta Dewi \& Sari (2015) yang menghasilkan kesimpulan bahwa kedua hal tersebut tidak saling memengaruhi.

Studi yang telah dilakukan oleh peneliti terdahulu menunjukkan hasil yang berbeda, atau belum konsisten. Hal inilah yang menarik perhatian penulis. Penulis melakukan penelitian ini tak lain adalah untuk menambah pustaka terdahulu tentang pengaruh Corporate Governance dan Kualitas Audit terhadap kecenderungan praktik tax avoidance.

\section{B. KAJIAN LITERATUR DAN TEORI}

\section{Agency Theory}

Jensen dan Meckling (1976) menjelaskan tentang teori hubungan keagenan (agency theory) yakni kerja sama (kontrak) yang dibentuk oleh satu atau lebih pemilik (principal) dengan orang lain, yang nantinya disebut sebagai agen, yang 
dipekerjakannya untuk melakukan pekerjaan atas nama pemilik dengan memberikan beberapa wewenang termasuk pengambilan keputusan.

Asumsi dalam teori agensi bahwa individu hanya termotivasi oleh kepentingan dirinya sendiri sehingga menimbulkan konflik kepentingan antara pemilik perusahaan (principal) dan manajemen sebagai agen (Darma, Tjahjadi, \& Mulyani, 2018). Perbedaan kepentingan yang ada akan menimbulkan adanya masalah keagenan. Agen (manajemen) dalam melaksanakan tugasnya memiliki tujuan pribadi yang bertentangan dengan tujuan pemilik dalam hal memaksimumkam kekayaan pemegang saham (Subagiastra, Arizona, \& Mahaputra, 2016). Hal ini berkaitan dengan imbal balik yang akan didapatkan oleh pihak manajemen. Dalam memperkerjakan manajemen, tentunya pemilik memberikan target yang harus dipenuhi, yakni jumlah laba. Oleh karena itu, manajemen akan berusaha keras agar target tersebut dapat tercapai atau bahkan melebihi. Di sisi lain, jika laba yang diperoleh besar maka beban yang akan dikeluarkan juga besar. Tentunya hal ini tidak sesuai dengan keinginan pihak principal. Maka, untuk menyeimbangkan perbedaan kepentingan ini perusahaan melakukan praktik tax avoidance (Tandean, 2015).

\section{Tindak Penghindaran Pajak (Tax avoidance)}

Tax avoidance yakni aksi legal untuk menurunkan pajak perusahaan dengan menggunakan kelemahan dari peraturan perpajakan yang berlaku (Sandy \& Lukviarman, 2015). Praktik ini dilakukan dengan manipulasi laba yang dihasilkan. Sistem perpajakan Indonesia yang menganut sistem self assesment akan memberikan kewenangan penuh kepada wajib pajak untuk menghitung, melaporkan, dan menyetorkan pajak terutangnya (Subagiastra, Arizona, \& Mahaputra, 2016). Sistem ini tentunya memberikan ruang yang lebih lebar bagi wajib pajak untuk memanipulasi laporan keuangan perusahaan agar beban pajak lebih ringan.

Tindakan tax avoidance disebabkan karena perarturan yang ada sekarang masih belum cukup kuat atau masih memiliki celah (area abu-abu) yang akhirnya dimanfaatkan untuk mengurangi pembayaran pajak perusahaan. Untuk mengurangi perilaku tax avoidance pemerintah menegaskan kepada wajib pajak, khususnya wajib pajak badan akan pentingnya Good Corporate Governance.

\section{Good Corporate Governance (GCG)}

Good Corporate Governance (GCG) merupakan mekanisme yang digunakan untuk mengatur dan mengawasi perusahaan melalui hubungan antara pemilik, manajemen, kreditur, pemerintah, karyawan, serta pihak lainnya yang memiliki kepentingan, baik internal ataupun eksternal sehingga dapat memaksimalkan nilai perusahaan (Sumantri, Anggraeni, \& Kusnawan, 2018). Tandean (2015) berpendapat bahwa GCG adalah tata kelola yang baik pada suatu perusahaan yang dilandasi oleh etika profesional dalam berusaha. Dengan kata lain, GCG merupakan pedoman tata kelola perusahaan yang baik, termasuk dalam hal pengambilan keputusan, yang mengatur 
hubungan antar elemen perusahaan, baik yang terlibat secara langsung ataupun tidak, dengan berlandaskan pada aturan-aturan yang berlaku. Oleh karena itu, GCG hendaknya oleh setiap entitas diterapkan dengan baik pula.

Hingga saat ini tata kelola perusahaan merupakan isu yang masih sangat menarik untuk terus dipelajari para pebisnis, akademisi, pengambil kebijakan, dan lain-lain (Sunarsih \& Oktaviani, 2016). Dalam jurnal penelitiannya mereka menambahkan, hal tersebut terkait dengan maraknya fenomena tentang penipuan serta kemerosotan bisnis yang terjadi akibat kesalahan yang dilakukan oleh manajemen eksekutif. Oleh karena itu, dengan adanya GCG diharapkan dapat menggurangi terjadinya masalah keagenan dan dapat memberikan perlindungan terhadap para stakeholder sehingga kemampuan bisnis dapat meningkat dan dapat membantu membantu mendorong laju

roda perekonomian negara. Penerapan GCG dalam perusahaan juga diharapkan dapat menurunkan praktik tax avoidance.

Variabel independen Corporate Governance yang dipakai dalam studi ini yakni Proporsi Komisaris Independen, Kepemilikan Institusional, dan Komite Audit.

\section{Proporsi Komisaris Independen dan Tax avoidance}

Komisaris independen yakni anggota dewan komisaris yang tidak memiliki hubungan dengan manajemen perusahaan yang dapat mempengaruhi kapasitasnya bertindak independen sebagai pengawas aktivitas manajemen agar tetap selaras dengan kepentingan para stakeholder (Avianita \& Fitria, 2020). Pengangkatan dewan komisaris dilakukan berdasarkan kriteria yang tercantum dalam Peraturan Otoritas Jasa Keuangan Nomor 30/POJK.05/2014 Tentang Tata Kelola Perusahaan yang Baik. Jumlah Komisaris Independen berdasarkan ketentuan Otoritas Jasa Keuangan Nomor 33/POJK.04/2014 yakni minimal $30 \%$ dari total dewan komisaris. Hal tersebut bersifat wajib.

Keberadaan komisaris independen diharapkan dapat meminimalisir tindakan manajemen yang tidak sesuai dengan prinsip GCG. Komisaris independen sebagai anggota yang bukan berasal dari intern perusahaan dianggap mempunyai risiko masalah keagenan yang rendah. Oleh karena itu, keberadaan komisaris independen diharapkan dapat mengurangi risiko praktik penghindaran pajak oleh perusahaan (Darma, Tjahjadi, \& Mulyani, 2018). Penelitian Sumantri, Anggraeni, \& Kusnawan, (2018), Sunarsih \& Oktaviani (2016), dan (Sandy \& Lukviarman, 2015) menunjukkan bahwa proporsi dewan komisaris memiliki pengaruh negatif terhadap praktik tax avoidance.

H1: Proporsi komisaris independen berpengaruh negatif terhadap kecenderungan praktik tax avoidance

\section{Kepemilikan Institusional dan Tax avoidance}

Kepemilikan institusional adalah pemegang saham suatu perusahaan yang berasal dari institusi atau lembaga lain. Kepemilikan institusional ini diharapkan mempunyai pengaruh signifikan dalam proses pengawasan pihak manajemen perusahaan sehingga 
dapat mengurangi praktik tax avoidance (Tandean, 2015). Semakin besar prosentase saham yang dimiliki oleh instansi lain, diharapkan dapat semakin menekan potensi tindak penghindaran pajak. Penelitian sejalan telah dilakukan oleh Avriliusqa (2020) serta Maretta, Widyastuti, \& Darmansyah (2019).

H2: Kepemilikan institusional berpengaruh negatif terhadap kecenderungan praktik tax avoidance

\section{Komite Audit dan Tax avoidance}

Komite audit dibentuk oleh dewan komisaris guna membantu tugas komisaris dalam melakukan pengawasan dan meningkatkan kualitas pengendalian perusahaan. Tugas lain yang menjadi cakupan komite audit adalah memastikan bahwa laporan keuangan yang diterbitkan perusahaan disajikan sesuai dengan SAK. Ketentuan Otoritas Jasa Keuangan Nomor 55/POJK.04/2015 Pasal 13 menyebutkan bahwa komite audit wajib melaksanakan rapat secara rutin yakni minimum satu kali dalam satu bulan.

Keberadaan komite audit bagi perusahaan go public diatur dengan ketentuan BAPEPAM Nomor Kep-29/PM/2004 dan Keputusan Menteri BUMN Nomor KEP103/MBU/2002 bagi Badan Usaha Milik Negara (Subagiastra, Arizona, \& Mahaputra, 2016). Umumnya, komite audit sebuah perusahaan sekurang-kurangnya terdiri atas tiga anggota, di mana satu anggota berkedudukan sebagai ketua yang juga merangkap sebagai komisaris independen perusahaan tersebut. Semakin banyak jumlah komite audit diharapkan dapat mengurangi kemungkinan praktik tax avoidance yang dilakukan oleh perusahaan. Hal ini didukung oleh penelitian yang dilakukan oleh Sunarsih \& Oktaviani (2016) dan Darma, Tjahjadi, \& Mulyani (2018).

H3: Komite audit berpengaruh negatif terhadap tax avoidance.

\section{Kualitas Audit dan Tax Avoidance}

Proses audit oleh KAP memiliki peran penting dalam sebuah perusahaan untuk memastikan praktik Good Corporate Governance (Avianita \& Fitria, 2020). Kualitas audit ditentukan oleh auditor (KAP) yang menangani laporan keuangan perusahaan. KAP yang tergabung sebagai anggota the big four memiliki hasil audit yang lebih dapat dihandalkan dan dipertanggungjawabkan daripada KAP yang bukan the big four. Semakin baik kualitas audit suatu laporan keuangan artinya kemungkinan adanya manipulasi beban pajak juga berkurang. Pernyataan tersebut didukung oleh penelitian oleh Sunarsih \& Oktaviani (2016) serta Sandy \& Lukviarman (2015).

H4: Kualitas audit berpengaruh negatif terhadap tax avoidance. 
Model penelitian sebagai berikut:

\section{Gambar 1. Model Penelitian}

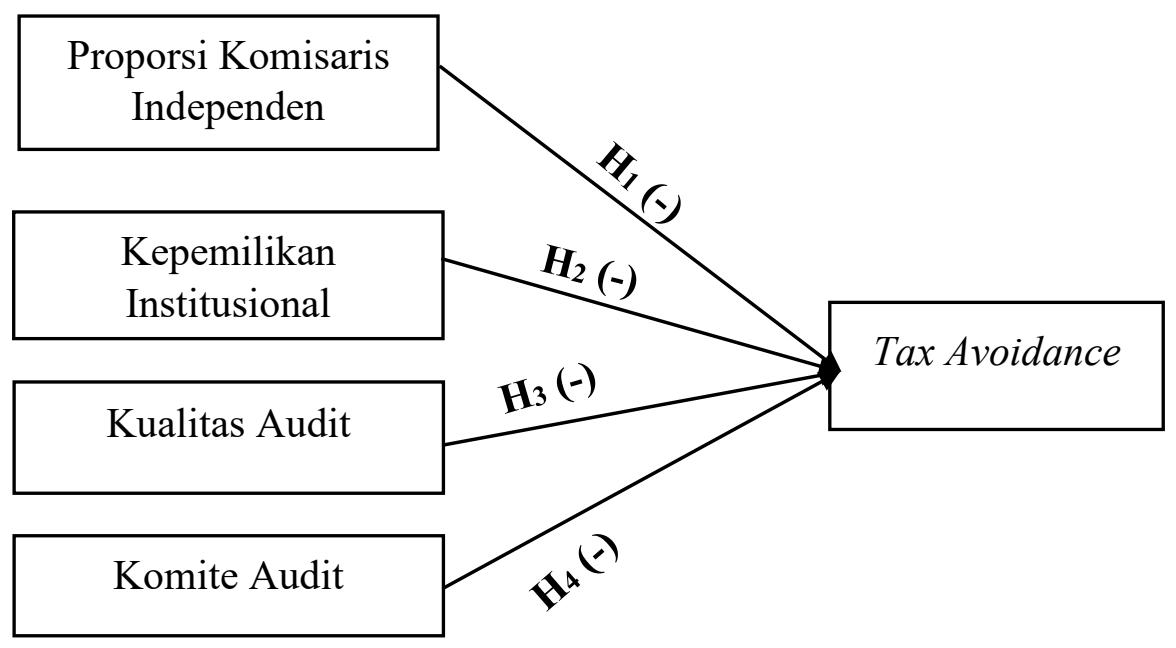

\section{METODE PENELITIAN}

\section{Populasi dan Sampel}

Populasi yang digunakan pada penelitian ini yakni perusahaan yang terdaftar di Bursa Efek Indonesia (BEI). Sampel yang digunakan adalah perusahaan manufaktur tahun 2015-2019. Teknik pengambilan sampel yang digunakan adalah purposive sampling. Adapun kriteria yang ditentukan oleh penulis adalah perusahaan manufaktur yang memiliki data yang lengkap selama lima tahun (2015 s/d 2019). Jumlah sampel yang digunakan sejumlah 179 perusahaan dengan jumlah observasi 498 perusahaan.

\section{Definisi Operasional dan Pengukuran Variabel}

Variabel independen dalam penelitian ini adalah Corporate Governance (CG) dan Kualitas Audit. Corporate Governance diproksikan dengan proporsi komisaris independen, kepemilikan institusional, dan komite audit. Variabel dependennya adalah penghindaran pajak (tax avoidance). 
Pengukuran masing-masing variabel dijelaskan dalam tabel 1 sebagai berikut:

\begin{tabular}{|c|c|c|c|}
\hline No. & $\begin{array}{c}\text { Jenis } \\
\text { Variabel }\end{array}$ & Variabel & Pengukuran \\
\hline 1 & Dependen & $\begin{array}{l}\text { Tax avoidance }(\mathrm{TA}) \\
\text { (Sandy \& Lukviarman, } \\
\text { 2015) }\end{array}$ & \\
\hline \multirow[t]{4}{*}{2} & Independen & $\begin{array}{l}\text { Proporsi Komisaris } \\
\text { Independen (PKI) } \\
\text { (Sandy \& Lukviarman, } \\
\text { 2015) }\end{array}$ & \\
\hline & & $\begin{array}{l}\text { Kepemilikan } \\
\text { Institusional (KI) } \\
\text { (Sandy \& Lukviarman, } \\
\text { 2015) }\end{array}$ & \\
\hline & & $\begin{array}{l}\text { Komite Audit } \\
\text { (Komdit) } \\
\text { (Tandean, 2015) }\end{array}$ & Jumlah komite audit perusahaan \\
\hline & & $\begin{array}{l}\text { Kualitas Audit } \\
\text { (Subagiastra, Arizona, } \\
\text { \& Mahaputra, 2016) }\end{array}$ & $\begin{array}{l}\text { - Jika perusahaan diaudit oleh KAP } \\
\text { The Big Four diberi angka } 1 \\
\text { - Jika perusahaan diaudit oleh KAP } \\
\text { non-The Big Four diberi angka } 0\end{array}$ \\
\hline
\end{tabular}

\section{HASIL DAN PEMBAHASAN}

Hasil statistik deskriptif dijelaskan dalam tabel 2 sebagai berikut:

Tabel 2. Hasil Statistik Deskriptif

\begin{tabular}{crrccc}
\hline Var & Minimum & Maksimum & Mean & Std. Deviasi & \multicolumn{1}{c}{ N } \\
\hline TA & 0,000182 & 0,971211 & 0,26537 & 0,142790 & 498 \\
PKI & 0,200 & 0,667 & 0,39774 & 0,088274 & 498 \\
KI & 0,044 & 0,998 & 0,70554 & 0,233221 & 498 \\
\hline Komdit & \multicolumn{1}{c}{2} & 5 & 3,04 & 0,321 & 498 \\
\hline
\end{tabular}

Berdasarkan tabel 2 di atas, dapat dilihat bahwa jumlah observasi (n) adalah sebanyak 498 perusahaan. Variabel TA memiliki nilai minimum sebesar 0,000182 dan nilai maksimum 0,971211 dengan rata-rata 0,26537 dan standar deviasi senilai 0,142790. PKI memiliki nilai minimum sebesar 0,200 dan maksimum sebesar 0,667. Kemudian, nilai rata-ratanya adalah sebesar 0,39774 dengan nilai standar deviasi 0,088274 . 
PKI memiliki nilai minimum sebesar 0,044 dengan nilai maksimum sebesar 0,998 . Nilai rata-ratanya adalah 0,70554 dengan standar deviasi sebesar 0,233221. Nilai minimum Komdit adalah 2 dengan nilai maksimum 5. Komdit memiliki rata-rata sebesar 3,04 dengan standar deviasi sebesar 0,321.

Tabel 3. Hasil Uji F

\begin{tabular}{lrrrrr}
\hline Model & $\begin{array}{c}\text { Sum of } \\
\text { Squares }\end{array}$ & df & $\begin{array}{c}\text { Mean } \\
\text { Square }\end{array}$ & F & Sig. \\
\hline Regression & 0,269 & 4 & 0,067 & 3,357 & 0,010 \\
\hline
\end{tabular}

Berdasarkan tabel 3 di atas, dapat diketahui bahwa nilai signifikansi data adalah sebesar 0,010 atau sebesar $1 \%$, yang artinya $\leq 5 \%$. Berdasarkan parameter yang telah ditentukan, dapat disimpulkan bahwa model regresi penelitian adalah layak. Dengan kata lain, secara menyeluruh atau simultan variabel PKI, KI, KA, dan Komdit memberikan pengaruh terhadap TA.

Tabel 4. Hasil Uji Determinasi

\begin{tabular}{ccccc}
\hline Model & R & R-Square & $\begin{array}{c}\text { Adj. } \\
\text { R-Square }\end{array}$ & $\begin{array}{c}\text { Std. Error of the } \\
\text { Estimate }\end{array}$ \\
\hline 1 & 0,163 & 0,027 & 0,019 & 0,141455 \\
\hline
\end{tabular}

Tabel 4 di atas,menunjukkan bahwa bahwa nilai Adjusted $R$-Square adalah 0,019 atau sebesar $1,9 \%$. Nilai tersebut memiliki arti bahwa variabel PKI, KI, KA, dan Komdit secara menyeluruh memberikan pengaruh terhadap TA sebesar 1,9\%., sedangkan sisanya sebesar $98,1 \%$ dipengaruhi oleh variabel lain yang tidak termasuk ke dalam model penelitian. Dengan kata lain, sebesar 98,1\% variabel TA dipengaruhi oleh variabel yang tidak diteliti.

Tabel 5. Hasil Uji Regresi

\begin{tabular}{lrr}
\hline \multicolumn{1}{c}{ Variabel } & Koefisien & t-statistik \\
\hline Const. & 0,300 & 4,288 \\
PKI & $0,145 * *$ & 2,008 \\
KI & $-0,080 *$ & $-2,879$ \\
KA & $0,024 * * *$ & 1,772 \\
Komdit & $-0,015$ & $-0,725$ \\
$* * *, * *, *$ Signifikan pada level $0,01,0,05$ dan 0,1 secara berurutan \\
Persamaan Model & & \\
TA $=0,300+0,145$ PKI $-0,080 \mathrm{KI}+0,024 \mathrm{KA}-0,015$ Komdit $+\mathrm{e}$ \\
\hline
\end{tabular}


Hipotesis pertama $\left(\mathrm{H}_{1}\right)$ adalah proporsi komisaris independen (PKI) berpengaruh signifikan negatif terhadap tax avoidance. Berdasarkan tabel hasil uji t di atas, nilai signifikansi untuk PKI adalah sebesar 0,045 atau sebesar 4,5\% yang berarti lebih kecil dari 5\%. Hal ini membuktikan bahwa proporsi komisaris independen berpengaruh signifikan terhadap penghindaran pajak. Namun, nilai koefisien regresi PKI menunjukkan nilai positif, yaitu sebesar 0,145 . Nilai ini menunjukkan bahwa PKI memberikan pengaruh signifikan positif terhadap penghindaran pajak. Oleh karena itu,

\section{hipoesis pertama ditolak.}

Hasil uji diatas memiliki makna bahwa semakin besar proporsi komisaris independen pada suatu perusahaan, maka praktik penghindaran pajak juga semakin besar. Hal ini tentunya tidak selaras dengan fungsi komisaris independen sebagai anggota yang tidak memiliki hubuangan dengan manajemen perusahaan yang bertugas melakukan pengawasan terhadap kegiatan bisnis perusahaan. Hal ini menunjukkan dewan komisaris independen kurang bisa menunjukkan sifat independennya sehingga keberadaanya kurang berarti bagi perusahaan dan fungsi pengawasan terhadap kecurangan menjadi kurang optimal. Keberadaan dewan komisaris independen disinyalir hanya untuk memenuhi ketentuan pemerintah terkait batas minimal proporsi komisaris independen (Akbar, 2019).

Hasil penelitian ini selaras dengan penelitian yang dilakukan oleh Akbar (2019) dan Setyawan (2018), yang menunjukkan hasil bahwa PKI berpengaruh positif terhadap penghindaran pajak. Namun, tidak dengan penelitian yang dilakukan oleh Sandy \& Lukviarman (2015), Sumantri, Anggraeni, \& Kusnawan (2018), dan Sunarsih \& Oktaviani (2016), yang menemukan pengaruh negatif.

Hipotesis kedua $\left(\mathrm{H}_{2}\right)$ adalah kepemilikan institusional (KI) berpengaruh signifikan negatif terhadap penghindaran pajak. Berdasarkan hasil uji data, nilai signifikansi KI sebesar 0,004 memiliki arti bahwa KI memberikan pengaruh yang signifikan terhadap penghindaran pajak. Di samping itu, koefisien regresinya yang bernilai -0,080 mengindikasikan bahwa KI berpengaruh negatif terhadap tax avoidance. oleh karena itu, hipotesis kedua diterima.

Hal tersebut memiliki makna bahwa semakin besar presentase kepemilikan institusional suatu perusahaan, maka potensi penghindaran pajak dapat berkurang. Adanya kepemilikan institusional pada suatu perusahaan memang diharapkan dapat menekan jumlah penghindaran pajak. Hal tersebut karena perusahaan akan cenderung merasa lebih terawasi jika institusi lain ikut andil dalam mengisi komposisi pemegang saham. Institusi lain tersebut tentunya tidak ingin mengalami kerugian sehingga akan terus melakukan pengawasan terhadap kinerja perusahaan. Hal ini tentunya dapat mendorong perusahaan untuk menghindari tindak kecurangan, termasuk penghindaran pajak yang dapat dilakukan dengan memanipulasi laba. Penelitian ini mendukung penelitian yang dilakukan oleh Avriliusqa (2020) dan Maretta, Widyastuti, \& Darmansyah (2019). Namun, hasil sebaliknya didapatkan pada penelitian yang dilakukan oleh Subagiastra, Arizona, \& Mahaputra (2016) dan Marfirah \& BZ (2016). 
Hipotesis ketiga $\left(\mathrm{H}_{3}\right)$ adalah komite audit (komdit) berpengaruh signifikan negatif terhadap penghindaran pajak. Berdasarkan hasil uji t di atas, dari segi arah memang komdit memiliki pengaruh negatif terhadap TA, yang ditunjukkan dengan nilai koefisien regresi sebesar $-0,015$. Namun, nilai signifikansinya menunjukkan angka sebesar 0,469 atau 46,9\%. Hal tersebut mengindikasikan bahwa komdit tidak berpengaruh signifikan terhadap tax avoidance. Oleh karena itu, dapat disimpulkan bahwa hipotesis ketiga ditolak.

Kesimpulan yang dapat ditarik adalah bahwa keberadaan komite audit pada perusahaan kurang dapat mengendalikan adanya praktik penghindaran pajak. Kemungkinan yang terjadi adalah komite audit kurang memiliki independensi sehingga kurang dapat membantu komisaris independen dalam melakukan pengawasan terhadap jalannya bisnis perusahaan. Di samping itu, kemungkinan komite audit dalam menjamin laporan keuangan yang disajikan sesuai dengan SAK masih kurang sehingga tidak dapat menekan adanya praktik tax avoidance.

Hasil penelitian ini mendukung hasil penelitian Dewi \& Sari (2015) dan Jefri \& Khoiriyah (2019) dan tidak sejalan dengan penelitian yang dilakukan oleh Sandy \& Lukviarman (2015), Oliviana \& Muid (2019), dan Darma, Tjahjadi, \& Mulyani (2018) yang menunjukkan komite audit memberikan pengaruh signifikan terhadap penghindaran pajak.

Hipotesis keempat $\left(\mathrm{H}_{4}\right)$ adalah kualitas audit $(\mathrm{KA})$ berpengaruh signifikan negatif terhadap tax avoidance (TA). Hasil analisis data menunjukkan yang sebaliknya. Nilai signifikansi KA yang menunjukkan angka 0,077 atau 7,7\% memiliki arti bahwa KA tidak berpengaruh signifikan terhadap penghindaran pajak. Di samping itu, nilai koefisien regresi KA pun menunjukkan nilai positif, yaitu sebesar 0,024. Dari uraian tersebut, dapat disimpulkan bahwa hipotesis keempat ditolak.

Kesimpulan yang dapat ditarik adalah bahwa diaudit oleh KAP The Big Four ataupun tidak, tidak memengaruhi adanya praktik tax avoidance. Hal ini kemungkinan terjadi karena perusahaan tidak merasa terhalangi jika akan memanipulasi laporan keuangannya walaupun nantinya laporan tersebut nantinya akan diaudit oleh KAP anggota The Big Four. Dengan catatan dalam memanipulasi laba tersebut masih dalam taraf wajar. Hal ini dapat terjadi karena KAP hanya menguji kewajaran suatu laporan keuangan.

Hasil penelitian ini mendukung penelitian oleh Maretta, Widyastuti, \& Darmansyah (2019) dan Avianita \& Fitria (2020). Namun, hasil yang berbeda ditunjukkan oleh Dewi \& Sari (2015), dan Jefri \& Khoiriyah (2019) yang menunjukkan hasil bahwa KA berpengaruh signifikan terhadap penghindaran pajak.

\section{E. KESIMPULAN DAN SARAN}

Penelitian ini menguji pengaruh corporate governance (diproksikan dengan variabel Proporsi Komisaris Independen, Kepemilikan Institusional, dan Komite Audit), serta Kualitas Audit terhadap kecenderungan perilaku penghindaran pajak ( $\operatorname{tax}$ 
avoidance) oleh perusahaan (diproksikan dengan variabel audit Berdasarkan hasil analisis data dan pembahasan di atas, dapat disimpulkan bahwa variabel Kepemilikan Institusional (KI) memiliki pengaruh negatif terhadap kecenderungan tax avoidance dan variabel Proporsi Komisaris Independen memiliki pengaruh positif terhadap kecemderungan tax avoidance. Variabel lain yakni Komite Audit (KI), dan Kualitas Audit (KA) tidak memiliki pengaruh terhadap tax avoidance. Hasil penelitian ini diharapkan dapat memperkaya studi terkait dengan perilaku penghindaran pajak perusahaan di Indonesia.

Penelitian ini memiliki keterbatasan dalam pengukuran corporate governance yakni hanya menggukan mekanisme corporate governance yakni Proporsi Komisaris Independen, Kepemilikan Instutusional, dan Komite Audit. Untuk pengembangan penelitian selanjutnya, variabel corporate governance dapat menggunakan proksi corporate governance index agar ukuran corporate governance bisa komprehensif.

\section{DAFTAR PUSTAKA}

Akbar, R. A. (2019). Pengaruh Good Corporate Governance, Profitabilitas, dan Leverage terhadap Tax avoidance. Skripsi EKonomi dan Bisnis.

Avianita, H., \& Fitria, A. (2020). Pengaruh Good Corporate Governance terhdapap Tax avoidance. Jurnal Ilmu dan Riset Akuntansi.

Avriliusqa, T. (2020). Pengaruh Good Corporate Governance (GCG) terhadap Penghindaran Pajak Perusahaan Manufaktur. Skripsi Ekonomi.

Darma, R., Tjahjadi, Y. D., \& Mulyani, S. D. (2018). Pengaruh Manajemen Laba, Good Corporate Governance, dan Resiko Perusahaan terhadap Tax avoidance. Jurnal Magister Akuntansi Trisakti.

Dewi, G. P., \& Sari, M. M. (2015). Pengaruh Eksekutif, Corporate Risk, dan Corporate Governance pada Tax avoidance. E-Jurnal Akuntansi Universitas Udayana.

Direktorat Jenderal Pajak. (2021, Januari). Diambil kembali dari DJP: www.pajak.go.id Enterprise, J. (2014). SPSS untuk Pemula. Jakarta: Kompas Gramedia.

Ghozali, I., \& Ratmono, D. (2013). Analisis Multivariat dan Ekonometrika Teori, Konsep dan Aplikasi dengan Eviews 8. Semarang: Universitas Diponegoro.

Jefri, \& Khoiriyah, Y. (2019). Pengaruh Good Corporate Governance dan Return on Assets terhadap Tax avoidance pada Perusahaan Manufaktur yang Terdaftar pada Bursa Efek Indonesia. Jurnal Penelitian dan Pengembangan Akuntansi.

Jensen, M. C., \& Meckling, W. H. (1976). Theory of The Firm: Managerial Behavior, Agency Cost, and Ownership Structure. Journal of Financial Economics 3.

KNKG. (2006). Pedoman Umum Good Corporate Governance Indonesia. Jakarta: Komite Nasional Kebijakan Governance. 
Maretta, D., Widyastuti, T., \& Darmansyah. (2019). Pengaruh Mekanisme Good Corporate Governance dan Kualitas Audit terhadap Tax avoidance. JIMEA Vol. 1, No. 1 .

Marfirah, D., \& BZ, F. S. (2016). Pengaruh Corporate Governance dan Leverage terhadap Tax avoidance pada Perusahaan Manufaktur yang Terdaftar di Bursa Efek Indonesia (BEI) Tahun 2011-2015. JIMEKA Vol. 1, No. 2.

Oliviana, A., \& Muid, D. (2019). Pengaruh Good Corporate Governance terhadap Tax avoidance. Diponegoro Journal of Accounting.

Priyono. (2008). Metode Penelitian Kuantitaif. Sidoarjo: Zifatama Publishing.

Radjab, E., \& Jam'an, A. (2017). Metodologi Penelitian Bisnis. Makassar: Lembaga Perpustakaan dan Penerbitan Universitas Muhammadiyah Makassar.

Sandy, S., \& Lukviarman, N. (2015). Pengaruh Corporate Governance terhadap Tax avoidance: Studi Empiris pada Perusahaan Manufaktur. JAAI.

Setyawan, F. D. (2018). Pengaruh Good Corporate Governance, Profitabilitas, dan Leverage terhadap Perilaku Tax avoidance: Dampak Penerapan Tax Amnesty. Skripsi Ekonomi dan Bisnis.

Setyawarno, D. (2016). Panduan Statistik Terapan untuk Penelitian Pendidikan. Yogyakarta: Pendidikan IPA FMIPA UNY.

Subagiastra, K., Arizona, I., \& Mahaputra, I. A. (2016). Pengaruh Profitabilitas, Kepemilikan Keluarga, dan Good Corporate Governance terhadap Penghindaran Pajak. Jurnal Ilmiah Akuntansi Vol. 1, No. 2.

Sugiyanto, \& Fitria, J. R. (2019). The Effect Karakter Aksekutif, Intensitas Modal, dan Good Corporate Governance terhadap Penghindaran Pajak.

Sumantri, F. A., Anggraeni, R., \& Kusnawan, A. (2018). Corporate Governance terhadap Tax avoidance pada Perusahaan Manufaktur yang Terdaftar di Bursa Efek Indonesia.

Sunarsih, U., \& Oktaviani, K. (2016). Good Corporate Governance in Manufacturing Companies Tax Avpidance. Etikonomi Vol. 15 (2).

Tandean, V. A. (2015). Pengaruh Good Corporate Governance dan Ukuran Perusahaan terhadap Tax avoidance.

Utama, M. S. (2016). Aplikasi Analisis Kuantitatif. Denpasar: CV Sastra Utama. 